\title{
Fluorescein dilaurate test of exocrine pancreatic function in cystic fibrosis
}

\author{
A M Dalzell, D P Heaf
}

\begin{abstract}
The fluorescein dilaurate test, a non-invasive test of exocrine pancreatic function, was carried out on 21 children with cystic fibrosis and pancreatic exocrine insufficiency, and 12 healthy siblings. The test clearly discriminated between the patients with cystic fibrosis and severe exocrine pancreatic insufficiency and the normal control subjects.
\end{abstract}

Duodenal intubation and pancreatic stimulation with secretin and cholecystokinin is the standard investigation of exocrine pancreatic function. ${ }^{1}$ The technique is, however, unpleasant for the patient, time consuming, expensive, and requires skill to carry out. This makes it an unsuitable investigation for routine clinical application, partiçularly in children. The fluorescein dilaurate test was developed in 1969 by Kaffarnik and Meyer-Bertenrath as an indirect method of assessing pancreatic function. ${ }^{2}$ The test has been used extensively in adults, ${ }^{3}$ but in only a small number of children, ${ }^{45}$ seven of whom had cystic fibrosis. ${ }^{5}$

We assessed the value of an adapted adult test in healthy control subjects and in children with cystic fibrosis known to have severe pancreatic insufficiency. The fluorescein doses, and fluid volumes used to maintain an adequate diuresis, were half those of the adult test.

\section{Patients and methods}

Twenty one children with cystic fibrosis (nine boys and 12 girls, mean age 10.5 years, range $4 \cdot 2-15 \cdot 2)$ were studied. Together with clinical features, two positive Gibson-Cooke sweat tests confirmed the diagnosis of cystic fibrosis. They all had steatorrhoea, shown on stool microscopy by the technique of Ghosh et $a l,{ }^{6}$ and they were all taking pancreatic enzyme supplements, and flucloxacillin as prophylaxis against staphylococcal colonisation. The multivitamins and vitamin $\mathrm{E}$ preparations that they were also taking daily were stopped for 24 hours before and during the test.

Twelve asymptomatic children (five boys and

Royal Liverpool Children's Hospital Alder Hey, Liverpool

A M Dalzel

D P Heaf

Correspondence to: Dr A M Dalzell, Royal Children's Hospital Herston Road,

Brisbane,

Queensland 4029,

Australia.

Accepted 12 February 1990

(Arch Dis Child 1990;65:788-9) seven girls, mean age $10 \cdot 2$ years, range $6 \cdot 2-15$ ), who were siblings of children with cystic fibrosis, served as control subjects.

Ethical approval for the study was granted by the Mersey Regional Ethics Committee and informed parental consent was obtained before each test.

TEST PROCEDURE

Adapted fluorescein dilaurate test for children

Half the recommended adult doses of fluores- cein dilaurate and non-esterified fluorescein were used. The test was performed on successive mornings. On the first day (test day) two capsules containing $0.125 \mathrm{mmol}$ of fluorescein dilaurate were taken, and on the second day (control day) one capsule containing $0.25 \mathrm{mmol}$ of non-esterified fluorescein was given.

Test day

Residual bladder urine was passed and discarded, and the children were given one or two cups of water or dilute fruit juice. The test began with a standard breakfast of one or two slices of bread or toast with $20 \mathrm{~g}$ of butter. Two blue capsules each containing $0.125 \mathrm{mmol}$ fluorescein dilaurate were taken together with a further cup of fluid. From the start of the test, for a timed period of 10 hours, all urine passed was collected in a plastic container. For the three hours after breakfast they were not allowed to eat or drink, but subsequently, they were encouraged to drink as much as they liked, and after five hours a normal diet was allowed. There were no restraints on activity, the only proviso being that all urine passed during the 10 hour period of the test, was collected.

\section{Control day}

The same procedure was adopted as for the test day, except that one red capsule containing 0.25 mmol of non-esterified fluorescein was taken with breakfast instead of the two blue capsules.

\section{LABORATORY ANALYSIS}

All urine was measured and $10 \mathrm{ml}$ samples were stored at $-20^{\circ} \mathrm{C}$ until analysis. An aliquot of 0.5 $\mathrm{ml}$ urine was mixed with $0.45 \mathrm{ml}$ of $0.1 \mathrm{~N}$ sodium hydroxide, and heated to $70^{\circ} \mathrm{C}$ for 10 $\mathrm{min}$ in a water bath. Free fluorescein was separated from its conjugated form (fluorescein glucuronide) and the optical extinction (E) at $492 \mathrm{~nm}$ ( $\lambda$ max for fluorescein) was compared with that of water using a spectrophotometer (Gilford stasar III). The excretion of fluorescein was calculated as: $\mathrm{E} 492 \times$ urine volume $/ 35$.

The denominator was derived from the dose, dilution, and molar absorption coefficient of fluorescein. Excretion on the test day was expressed as a percentage of excretion on the control day ( $\mathrm{T} / \mathrm{K}$ quotient).

STATISTICAL METHODS

Results are presented as a $\mathrm{T} / \mathrm{K}$ quotient (SD), which represents the mean excretion of fluorescein in urine on the test $(\mathrm{T})$ day, as a percentage of the excretion on the control $(\mathbf{K})$ day. Differ- 


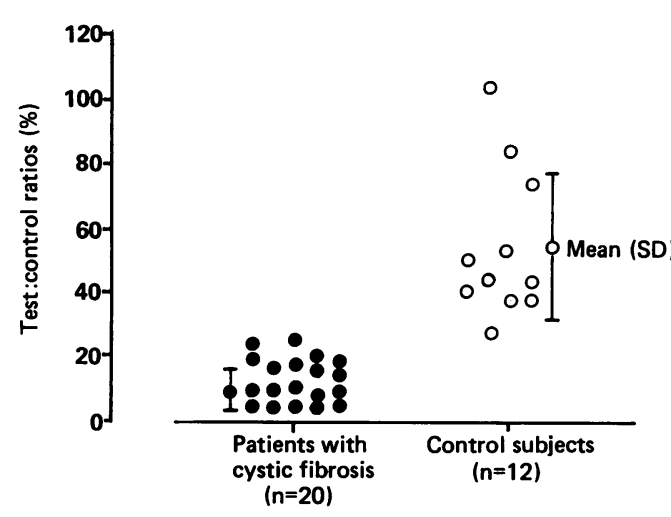

Fluorescein dilaurate excretion ratios in patients with cystic fibrosis and normal subjects.

ences between patients with cystic fibrosis and controls were assessed by Student's $t$ test.

\section{Results}

Twenty one patients with cystic fibrosis and 12 control subjects completed fluorescein dilaurate tests. One patient with cystic fibrosis was withdrawn from the study because of vomiting the test capsules. No other side effects were reported by any of the participants or observers.

The mean volume of urine collected within 10 hours for the test day was $1181 \mathrm{ml}$ (range $380-2750$ ), and the mean volume of urine collected on the control day was $916 \mathrm{ml}$ (range 515-2350). Although the sample sizes are small, the $T / K$ values were normally distributed.

The mean $T / K$ (SD) value for patients with cystic fibrosis was $9.9(6.4)$, and that for the control group was 54 (23) $(\mathrm{p}<0.0001)$ (figure).

\section{Discussion}

Indirect methods of assessing pancreatic exocrine function are attractive because of their non-invasive nature. Twelve healthy control subjects completed the test using half the recommended adult dose. A $\mathrm{T} / \mathrm{K}$ value of 30 ; which has been proposed as the 'cut-off' between normal adult subjects and patients with pancreatic exocrine dysfunction, also seems to be applicable in this age group, although more tests need to be carried out in children to establish a normal range.

Twenty tests were completed by a highly selected population of patients with severe pancreatic insufficiency whose symptoms were normally controlled with pancreatic enzyme supplements. Because only patients with severe pancreatic insufficiency were tested, separation between this group and normal subjects was clear. If a broader range of patients were to have the test carried out, however, those with less severe pancreatic insufficiency might be less easy to discriminate.

Previous studies, in which the adult fluorescein dilaurate test had been used in children, ${ }^{45}$ have all found difficulties in implementation, particularly in encouraging an adequate fluid intake. We reduced the dose of fluorescein and found no difficulties in conducting the tests. Spending a weekend collecting urine was far more preferable for some than being subject to the venepuncture that would be necessary for serum estimations of fluorescein.

In common with previous studies in adults ${ }^{3}$ we found that taking fluorescein dilaurate by mouth was not associated with any side effects in children, and the test and urine analysis were simple to carry out. Further studies are required to assess the specificity of this test by screening children under investigation for gastrointestinal disease.

AMD was in receipt of a cystic fibrosis research fellowship. The fluorescein dilaurate test kits were supplied by Charwell Pharmaceuticals Limited, Alton, Hants, England.

1 Hadorn B, Zoppi G, Shmerling DH, Prader A, McIntyre I, Anderson CM. Quantitative assessment of exocrine pancreatic

2 Kaffarnik H, Meyer-Bertenrath JG. Zur Methodik und klinischen Bedeutung eines neuen Pankreaslipase-Tests mit Fluoresceindilaurinsaureester. Klin Wochenschr 1969;47: 221-3.

3 Lankisch PG, Schreiber A, Otto J. Pancreolauryl test evaluation of a tubeless pancreatic function test in comparison with other indirect and direct tests for exocrine pancreatic function. Dig Dis Sci 1983;28:490-3.

4 Neis P, Zeuss F. Uber die Anwendbarkeit von FluoresceinDilaurat zur exokrinen Pankreasfunktionsprüfung bei Kindern. Monatsschr Kinderheilkd 1981;129:347-8.

5 Schönberger W, Weitzel D. Diagnose der exokrinen Pankreasinsuffizienz mit Fluorescein-Dilaurat bei Patienten mit cystischer Fibrose. Monatsschr Kinderheilkd 1980; 128: 195-8.

6 Ghosh SK, Littlewood JM, Goddard D, Steel AE. Stool microscopy in screening for steatorrhoea. $\mathcal{F}$ Clin Pathol
$1977 ; 30: 749-53$. 